\title{
Ações de cuidado e necessidades essenciais de prematuros após a alta hospitalar: revisão de escopo
}

\author{
Actions caring and essential needs of premature infants after hospital discharge: scoping review \\ Acciones de atención y necesidades esenciales de prematuros después del alta hospitalaria: revisión \\ de alcance
}

Cynthia Márcia Romano Faria Walty ${ }^{1,2}$ (1) Nayara Luiza Henriques ${ }^{1}$ (D) Natália de Mesquita Melo Coimbra ${ }^{1}$ (1) Patrícia Pinto Braga ${ }^{3}$ (1)

Maria de La Ó Ramallo Veríssimo ${ }^{4}$ (1) Elysângela Dittz Duarte ${ }^{5}$ (1)

1. Universidade Federal de Minas Gerais. Belo Horizonte, MG, Brasil.

2. Hospital Sofia Feldman. Belo Horizonte, MG, Brasil.

3. Universidade Federal de São João Del-Rei. Divinópolis, MG, Brasil.

4. Universidade de São Paulo, Departamento de Enfermagem Materno Infantil e Psiquiátrica, Escola de Enfermagem. São Paulo, SP, Brasil.

5. Universidade Federal de Minas Gerais, Departamento de Enfermagem Materno Infantil e Saúde Pública, Escola de Enfermagem. Belo Horizonte, MG, Brasil.

Autor correspondente:

Cynthia Márcia Romano Faria Walty

E-mail: cynthiaromano28@yahoo.com.br

Recebido em 21/10/2020.

Aprovado em 24/05/2021.

DOI:https://doi.org/10.1590/2177-9465-EAN-2020-0412

\section{Resumo}

Objetivo: identificar e analisar as ações de cuidado às crianças nascidas prematuras, após a alta hospitalar, realizadas pelos familiares e profissionais de saúde. Método: revisão de escopo, desenvolvida em dezembro de 2019, segundo as orientações do Joanna Briggs Institute e do guia internacional PRISMAScR. Foram investigados estudos originais, publicados em inglês, espanhol ou português, de 2013 a 2019, nas bases CINAHAL, Medline, LILACS, Cochrane, Scopus, Web of Science. Os 21 artigos incluídos foram submetidos à análise direcionada de conteúdo apoiada pelo referencial das necessidades essenciais das crianças. Resultados: predominaram ações para proteção física e segurança (20 artigos), comunidades estáveis e amparadoras (dez artigos), seguidas de relacionamentos sustentadores contínuos (seis artigos), experiências que respeitem as diferenças individuais (quatro artigos) e experiências adequadas ao desenvolvimento (dois artigos). Ações para o estabelecimento de limites, organização e expectativas não foram identificadas nos estudos. Conclusões e implicações para a prática: as ações de cuidado contemplam, principalmente, a dimensão física. Ao considerar o cuidado integral e os achados desta revisão são necessários avanços nas ações para o atendimento de outras dimensões da vida dos prematuros como a emocional e a social.

Palavras-chave: Recém-Nascido Prematuro; Cuidado da Criança; Saúde da Criança; Alta Hospitalar; Cuidado de Enfermagem

\section{Abstract}

Objective: to identify and analyze the actions taken by family and health professionals to care for children born prematurely after hospital discharge. Method: a scoping review, developed in December 2019, according to the Joanna Briggs Institute guidelines and the international PRISMAScR guide. Original studies, published in English, Spanish or Portuguese from 2013 to 2019 in CINAHAL, Medline, LILACS, Cochrane, Scopus, Web of Science databases were investigated. The 21 included articles were submitted to directed content analysis supported by the framework of essential needs of children. Results: actions for physical protection and safety (20 articles), stable and supportive communities (10 articles) $n$ followed by ongoing supportive relationships (6 articles), experiences that respect individual differences (4 articles), and developmentally appropriate experiences (2 articles) predominated. Actions for boundary setting, organization, and expectations were not identified in the studies. Conclusions and implications for practice: the care actions contemplate the physical dimension. Considering comprehensive care and the findings of this review, advances in actions are needed to adress other dimensions of preterm infant's life, such as emotional and social.

Keywords: Infant Premature; Infant Care; Child Health; Hospital Discharge; Nursing Care.

\section{Resumen}

Objetivo: identificar y analizar las acciones de cuidado niño prematuro realizadas por familiares y profesionales de la salud después del alta hospitalaria. Método: revisión de alcance, desarrollada en diciembre de 2019, según las directrices del Instituto Joanna Briggs y laguía internacional PRISMAScR. Se investigaron los estudios originales publicados en inglés, español o portugués de 2013 a 2019 en CINAHAL, Medline, LILACS, Cochrane, Scopus, Web of Science. Los 21 artículos incluidos se sometieron a un análisis de contenido específico apoyado por las necesidades esenciales de los niños. Resultados: prevalecieron las acciones para la protección física y la seguridad (20 artículos) y las comunidades estables y solidarias (10 artículos), seguidas de relaciones de apoyo continuas ( 6 artículos), experiencias que respetan las diferencias individuales (4 artículos) y experiencias apropiadas para el desarrollo (2 artículos). En los estudios no se identificaron acciones para establecer límites, organización y expectativas. Conclusiones e implicaciones para lapráctica: las acciones de cuidado incluyen, principalmente, ladimensión física. Al considerar la atención integral e los allazgos, es necesario avanzar para involucrar otras dimensiones de la vida del prematuro como la emocional y la social.

Palabras clave: Recien Nacido Prematuro; Cuidado del Niño; Salud del Niño; Alta del Paciente; Cuidado de Enfermería 


\section{INTRODUÇÃO}

As crianças, independentemente de sua classe social, origem étnica, condição física e mental, apresentam necessidades essenciais ao seu desenvolvimento integral ${ }^{1}$. A busca por um cuidado integral, que favoreça o desenvolvimento infantil em todo o seu potencial, exige a apropriação de aportes conceituais que considerem as complexas dimensões do processo de crescimento e desenvolvimento e o reconhecimento desse público como sujeitos de cuidados e de direitos.

Para tanto, identificamos, no modelo das necessidades essenciais das crianças, que na infância é preciso: relacionamentos sustentadores contínuos; proteção física, segurança e regras; respeito às diferenças individuais; estabelecimento de limites, organização e expectativas; provimento de experiências adequadas ao desenvolvimento; de comunidades estáveis, amparadoras e de continuidade cultural ${ }^{1}$.

Reconhecer as necessidades essenciais das crianças ${ }^{1}$, no cuidado em saúde, é uma estratégia promotora do crescimento e desenvolvimento saudável e de valorização das singularidades. Nesse contexto, se inserem as crianças nascidas prematuras, egressas de cuidados intensivos neonatais, que dependem de cuidados da família e de profissionais dos serviços de saúde, seja no seguimento ambulatorial ou atenção primária.

As ações e avanços assistenciais na atenção ao pré-termo repercutiram nas taxas de sobrevivência e manejo clínico em Unidades Neonatais, contudo uma análise ampliada sobre as suas necessidades ao longo da vida precisa ser elucidada ${ }^{2}$. Estudos sobre o crescimento e desenvolvimento, desse grupo infantil, nos últimos anos, sinalizam para estratégias que precisam ser adotadas para a continuidade do cuidado após a alta hospitalar ${ }^{3}$ como: necessidade de educação em saúde da família de prematuros ${ }^{4}$ e necessidades nutricionais de crianças nascidas prematuramente durante os primeiros anos de vida ${ }^{5,6}$.

Destaca-se que poucos estudos têm se ocupado em analisar o cuidado em saúde a partir do modelo das necessidades essenciais. Entretanto, este pode ser um referencial para uma assistência integral ${ }^{7}$, além de favorecer o cuidado seguro das crianças no domicílio, após a alta hospitalar, no primeiro ano de vida ${ }^{8}$.

Considerando o exposto, reconhecemos que identificar, na literatura nacional e internacional, as ações de cuidados direcionadas às crianças nascidas prematuras após a alta hospitalar e analisá-las a partir do referencial das necessidades essenciais, evidenciará como tem se configurado o cuidado a elas e, em que medida, ele tem se aproximado ao atendimento dessas necessidades. Esses achados podem contribuir para gerar novas questões de pesquisas e nortear a prática profissional.

Assim, o objetivo deste estudo foi identificar e analisar as ações de cuidado às crianças nascidas prematuras após a alta hospitalar, realizadas pelos familiares e profissionais de saúde.

\section{MÉTODO}

Trata-se de uma revisão de escopo orientada pelo Joanna Briggs Institute, Manual for Evidence Synthesis ${ }^{9}$ e pelo guia internacional PRISMAScR ${ }^{10}$. O protocolo de revisão foi registrado no Open Science Framework (OSF) e pode ser acessado em (https://osf.io/e5u64). O estudo de escopo (scopingreview) objetiva mapear conceitos de diversas áreas de conhecimento, bem como limites conceituais e examina a extensão, alcance e natureza das investigações. Sumariza e divulga os dados da pesquisa e identifica lacunas de estudos já publicados ${ }^{11}$.

Conforme orientação do JBI, esta revisão foi realizada em cinco etapas que constaram da elaboração da pergunta de pesquisa, identificação dos estudos relevantes, seleção dos estudos identificados, análise dos dados e síntese dos dados ${ }^{9}$.

A pergunta norteadora foi: quais ações de cuidado de familiares e profissionais da saúde têm sido direcionadas às crianças nascidas prematuras após a alta hospitalar? Foi utilizada a estratégia de População, Conceito e Contexto (PCC) e incluídos os estudos que apresentaram como população: recém-nascidos pré-termos, suas famílias e profissionais de saúde que os assistem; como conceito: ações de cuidados de familiares e de profissionais para o desenvolvimento integral dessas crianças; e, como contexto: o cuidado de crianças nascidas prematuras após a alta hospitalar, mais especificamente, no domicílio e serviços de saúde como a Atenção Primária em Saúde (APS), e os serviços especializados: hospitais e ambulatórios de seguimento especializados em acompanhamento do crescimento e desenvolvimento de egressos de Unidades de Terapia Intensiva Neonatais.

A estratégia de busca objetivou encontrar estudos originais, publicados em inglês, espanhol ou português nas bases de dados CINAHAL, Medline (via PUBMED), LILACS, Cochrane, Scopus, Web of Science, publicados entre os anos de 2013 a 2019. Essa etapa foi realizada em dezembro de 2019, utilizandose os seguintes descritores em inglês "Infant, Premature", "InfantCare", "Child Health", "Paciente Discharge" nas bases de dados incluídas. Os títulos e resumos foram lidos para inclusão dos estudos e foi utilizado o software Rayyan para a seleção dos estudos na revisão ${ }^{12}$.

Os critérios de inclusão para a pré-seleção dos estudos foram: estudos em inglês, português ou espanhol, publicados em periódicos e que abordassem o tema de cuidados em saúde da criança nascida prematura após a alta hospitalar. Foram excluídos os artigos não primários, como os de opinião e as revisões, e aqueles que, após a leitura na íntegra, não atendiam aos requisitos de população, conceito e contexto (PCC), conforme o protocolo elaborado para esta revisão.

Foram identificados 435 artigos publicados nos últimos cinco anos nas bases de dados pesquisadas. A Figura 1 apresenta o fluxo realizado para seleção dos artigos incluídos neste estudo. Foram excluídos 54 por duplicidade, 350 por não atenderem ao objetivo do estudo, sendo 143 por estarem fora do período estabelecido, 98 por contexto inadequado, ou seja, ter sido realizado durante a hospitalização, 58 por não apresentarem relação com o conceito escolhido, 11 por terem uma população 


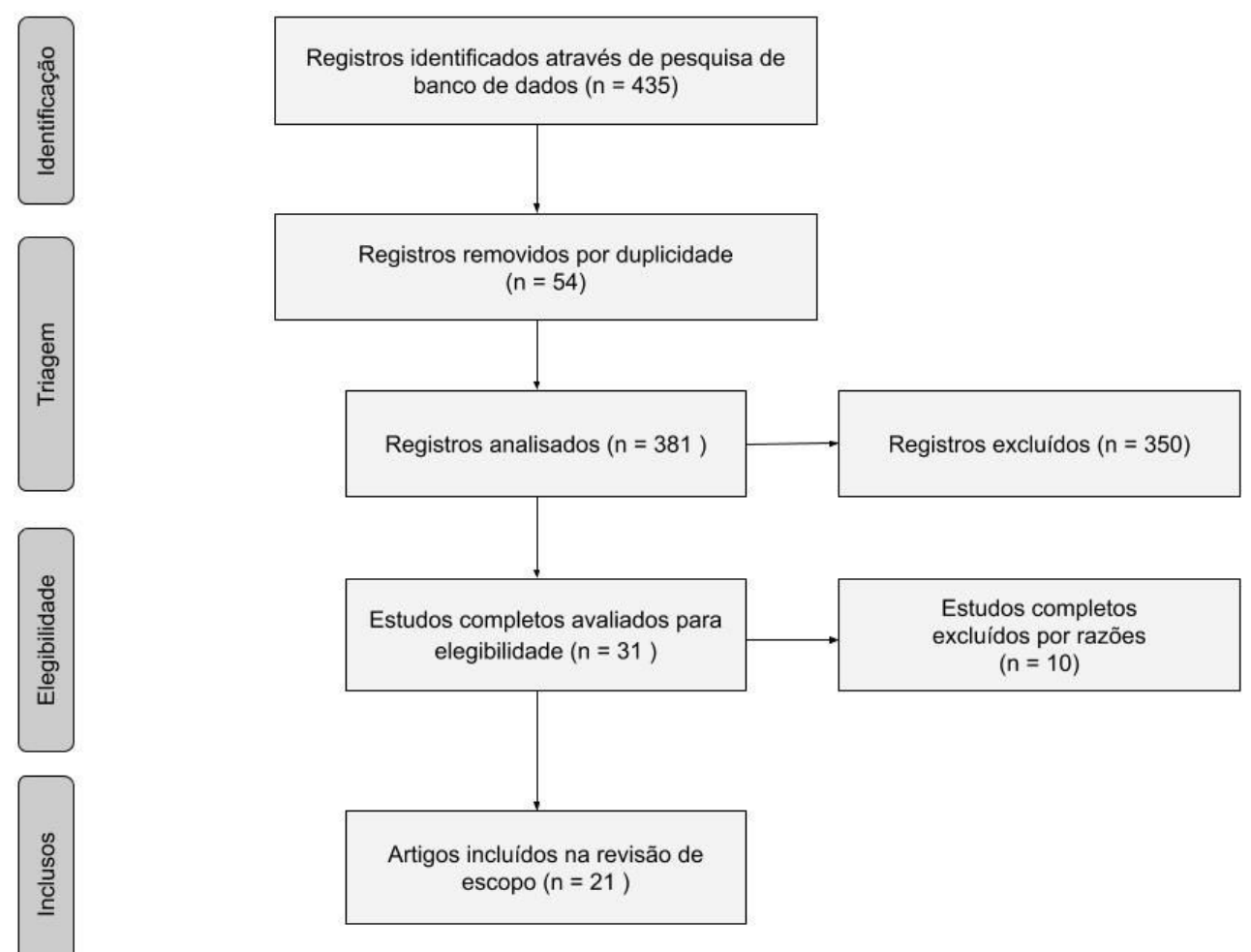

Figura 1 - Diagrama de fluxo PRISMA ${ }^{10}$ (adaptado SCR) do processo de seleção do estudo. Belo Horizonte, MG, Brasil, 2020. Fonte: Dados da Pesquisa, 2020.

que não atendia aos objetivos, 40 por desenho de estudo inadequado. Dessa forma, foram lidos 31 artigos na íntegra. Ao final, 21 foram inclusos na revisão, uma vez que dez artigos foram excluídos por não terem atendido aos critérios de inclusão.

A seleção inicial dos estudos, a partir da leitura de 381 títulos e resumos, por duas pesquisadoras, resultou na identificação de 31 produções, processo que foi validado por uma terceira pesquisadora. Seguiu-se, então, com a leitura na íntegra, por duas pesquisadoras de forma independente, o que permitiu a identificação de uma amostra final de 21 artigos. Quando aconteciam dissensos, eram analisados pelos autores deste artigo.

A amostra final de artigos foi submetida à análise de conteúdo direta ${ }^{13}$. Primeiramente, foram identificadas as ações de cuidado ofertadas às crianças nascidas prematuras após a alta hospitalar descritas nos artigos. Um sistema de códigos foi elaborado, apoiado pelas seis necessidades essenciais de Brazelton e Greenspan ${ }^{1}$. Em seguida, realizou-se a codificação das ações de cuidado a partir do referencial das necessidades essenciais, conforme exemplificado pelo Quadro 1. A codificação independente foi realizada por Walty, CMRF e Henriques, NL com posterior validação intercodificadores. Todo esse processo teve o suporte do software MaxQDA versão 18.015. Os segmentos codificados foram validados por Veríssimo, MDL quanto à aplicação do referencial teórico. Veríssimo, MDLé a pesquisadora brasileira referência para o Modelo das Necessidades Essenciais das Crianças.

\section{RESULTADOS}

Os 21 artigos incluídos nesta revisão são apresentados no Quadro 2, com identificação do objetivo, tipo de estudo, contexto de cuidado e da amostra, além das necessidades essenciais identificadas.

A abordagem quantitativa representou $62 \%$ dos estudos ( $n$ 13), enquanto a qualitativa foi adotada em 38\% (n 8). Quanto aos países de publicação, seis ${ }^{14,20,21,24,29,33}$ foram realizados no Brasil, três ${ }^{19,31,32}$ nos Estados Unidos, dois ${ }^{30,34}$ na Espanha, dois ${ }^{18,27}$ na ltália, $u^{35}{ }^{35}$ no Canadá, um ${ }^{23}$ na Suíça, um ${ }^{28}$ no Kênia, um ${ }^{17}$ na Dinamarca, $u^{26}{ }^{26}$ na Romênia, um ${ }^{16}$ na Colômbia, um ${ }^{22}$ na Austrália e Gana, e $u^{25}$ na Turquia. Todos os estudos do Brasil foram de abordagem qualitativa. Quanto ao ano de publicação, dois estudos ${ }^{16,17}$ foram publicados em 2018, nove estudos ${ }^{18-26}$ em 2017, seis estudos ${ }^{27-32} \mathrm{em}$ 2016, um ${ }^{33}$ em 2015, dois ${ }^{14,34}$ em 2014 e um ${ }^{35}$ em 2013.

Os artigos analisados apresentaram como população do estudo: recém-nascido prematuro (11 artigos $^{16,18,19,25-28,31-33,34}$ ), suas famílias (nove artigos ${ }^{14,17,20-23,29,30,35}$ ) e profissionais de saúde (um artigo ${ }^{24}$ ). A maioria dos estudos foi conduzida em apenas um contexto de cuidado sendo: dez estudos ${ }^{16,18,19,25-28,31-33}$ realizados no Ambulatório de Seguimento, sete estudos ${ }^{14,17,20-23,29}$ realizados no domicílio e um estudo ${ }^{24}$ realizado na Unidade Básica de Saúde. Dos três artigos ${ }^{30,34,35}$ que tiveram mais de um contexto de cuidado, o hospital e o domicílio foram cenários em comum em dois artigos ${ }^{30,34}$ e o ambulatório e o hospital em um artigo ${ }^{35}$ Os estudos que tiveram apenas o hospital como local de estudo 
Quadro 1. Codificação das ações de cuidado de acordo com as necessidades essenciais das crianças. Belo Horizonte, MG, Brasil, 2020.

\begin{tabular}{|c|c|c|c|}
\hline Autores & Desenho & Trecho que revela a ação de cuidado & $\begin{array}{l}\text { Necessidade essencial } \\
\text { identificada }\end{array}$ \\
\hline \multirow[b]{2}{*}{$\begin{array}{l}\text { Anelize Helena } \\
\text { Sassá et al. }{ }^{14} \text { Brasil } \\
\text { (2014) }\end{array}$} & \multirow[b]{2}{*}{$\begin{array}{l}\text { Estudo } \\
\text { qualitativo } \\
\text { (convergente } \\
\text { assistencial) }\end{array}$} & $\begin{array}{l}\text { "As famílias se preocupavam em manter a criança } \\
\text { protegida de doenças por intermédio da vacinação" }\end{array}$ & $\begin{array}{l}\text { Necessidade de proteção } \\
\text { física, segurança e } \\
\text { regulamentação }\end{array}$ \\
\hline & & $\begin{array}{l}\text { "Foram realizadas orientações sobre as } \\
\text { especificidades do bebê nascido de muito baixo } \\
\text { peso e os cuidados que poderiam ser conduzidos } \\
\text { de maneira convencional, respeitando se, dentro } \\
\text { do possível, as práticas familiares e culturais do } \\
\text { contexto em que o bebê estava inserido" }\end{array}$ & $\begin{array}{l}\text { Necessidade de comunidades } \\
\text { amparadoras e de } \\
\text { continuidade cultural }\end{array}$ \\
\hline
\end{tabular}

Quadro 2. Descrição dos estudos selecionados quanto ao objetivo, tipo de estudo, contexto de cuidado, amostra do estudo e necessidades essenciais relacionadas aos cuidados descritos. Belo Horizonte, MG, Brasil, 2020.

\begin{tabular}{|c|c|c|c|c|c|}
\hline $\begin{array}{l}\text { Código } \\
\text { do Artigo }\end{array}$ & Objetivo & Tipo de Estudo & Amostra & Contexto & $\begin{array}{l}\text { Necessidades } \\
\text { essenciais* } \\
\text { relacionadas } \\
\text { aos cuidados } \\
\text { descritos } \\
\end{array}$ \\
\hline $\mathrm{A} 01^{16}$ & $\begin{array}{l}\text { Descrever o atendimento de } \\
\text { recém-nascidos prematuros } \\
\text { (RNPT) no Programa Canguru } \\
\text { até os } 12 \text { meses }\end{array}$ & $\begin{array}{c}\text { Estudo quantitativo } \\
\text { (coorte, } \\
\text { prospectivo) }\end{array}$ & $\begin{array}{c}1138 \text { RNPT e/ou } \\
\text { baixo peso }\end{array}$ & Ambulatorial & NPF \\
\hline \multirow{4}{*}{$\mathrm{A} 02^{17}$} & \multirow{4}{*}{$\begin{array}{l}\text { Explorar as experiências } \\
\text { dos pais com o serviço de } \\
\text { assistência domiciliar neonatal } \\
\text { remota (telessaúde) usando } \\
\text { comunicação on-line }\end{array}$} & \multirow{4}{*}{ Estudo qualitativo } & \multirow{4}{*}{49 pais de RNPT } & \multirow{4}{*}{ Domiciliar } & NPF \\
\hline & & & & & NCE \\
\hline & & & & & $\mathrm{NEI}$ \\
\hline & & & & & NRS \\
\hline & Avaliar os efeitos da & & & & NPF \\
\hline $\mathrm{A} 03^{18}$ & $\begin{array}{c}\text { intervenção do "CareToy" no } \\
\text { desenvolvimento motor e } \\
\text { visual precoce em prematuros } \\
\text { entre } 3 \text { e } 6 \text { meses de idade } \\
\text { corrigida }\end{array}$ & $\begin{array}{l}\text { Estudo quantitativo } \\
\text { (Ensaio clínico } \\
\text { randomizado) }\end{array}$ & 41 RNPT & Ambulatorial & NEI \\
\hline $\mathrm{A} 04^{19}$ & $\begin{array}{c}\text { Caracterizar os serviços de } \\
\text { terapia precoce para RNPT e } \\
\text { definir os fatores relacionados } \\
\text { ao seu acesso }\end{array}$ & $\begin{array}{l}\text { Estudo quantitativo } \\
\text { (transversal) }\end{array}$ & $\begin{array}{c}57 \text { RNPT com } \\
\text { menos de } 30 \\
\text { semanas egressos } \\
\text { da UTIN }\end{array}$ & $\begin{array}{l}\text { Hospitalar } \\
\text { - Avaliação } \\
\text { ambulatorial }\end{array}$ & NPF \\
\hline \multirow{3}{*}{$\mathrm{A} 05^{20}$} & \multirow{3}{*}{$\begin{array}{l}\text { Analisar aspectos da vida } \\
\text { cotidiana relacionada ao } \\
\text { aleitamento materno exclusivo } \\
\text { de RNPT após a alta hospitalar }\end{array}$} & \multirow{3}{*}{ Estudo qualitativo } & \multirow{3}{*}{14 mães de RNPT } & \multirow{3}{*}{ Domiciliar } & NPF \\
\hline & & & & & NCE \\
\hline & & & & & NRS \\
\hline \multirow{3}{*}{$\mathrm{A} 06^{21}$} & \multirow{3}{*}{$\begin{array}{l}\text { Apreender as representações } \\
\text { do pai frente ao cuidado do } \\
\text { filho prematuro nos primeiros } \\
\text { dias após a alta hospitalar }\end{array}$} & \multirow{3}{*}{ Estudo qualitativo } & \multirow{3}{*}{$\begin{array}{c}07 \text { pais de RNPT } \\
\text { hospitalizados em } \\
\text { uma UTIN }\end{array}$} & \multirow{3}{*}{ Domiciliar } & NPF \\
\hline & & & & & NCE \\
\hline & & & & & NRS \\
\hline
\end{tabular}

Fonte: Dados da Pesquisa, 2020. *Legenda. Códigos atribuídos às necessidades essenciais: NPF = Necessidade de Proteção Física Segurança e Regulamentação; NCE = Necessidades de comunidades estáveis, amparadoras e de continuidade cultural; NRS = Necessidade de relacionamentos sustentadores contínuos; $\mathrm{NEI}=$ Necessidades de experiências que respeitem as diferenças individuais; NEA = Necessidade experiências adequadas ao desenvolvimento. 
Quadro 2. Continuação...

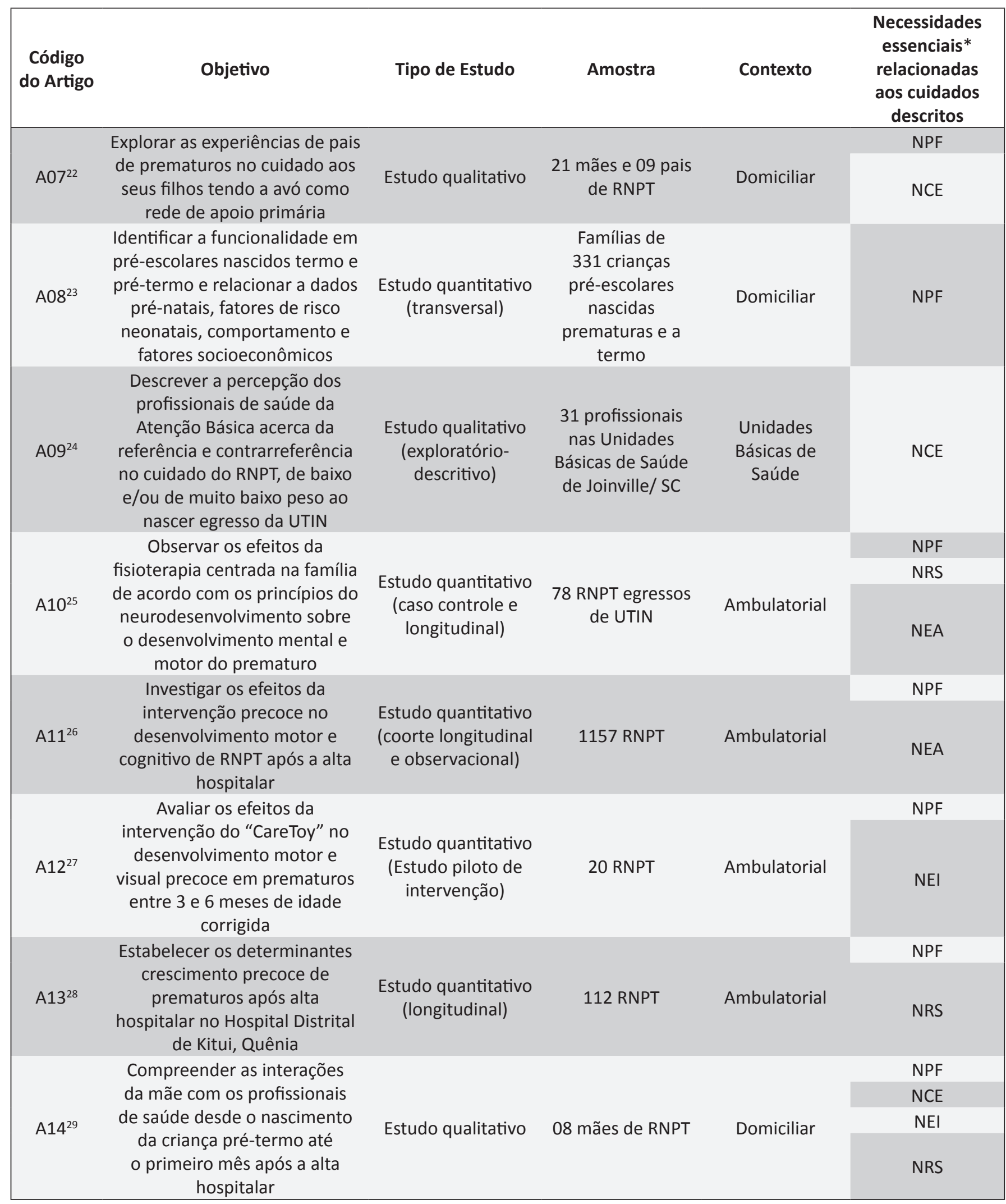

Fonte: Dados da Pesquisa, 2020. *Legenda. Códigos atribuídos às necessidades essenciais: NPF = Necessidade de Proteção Física Segurança e Regulamentação; NCE = Necessidades de comunidades estáveis, amparadoras e de continuidade cultural; NRS = Necessidade de relacionamentos sustentadores contínuos; $\mathrm{NEI}=$ Necessidades de experiências que respeitem as diferenças individuais; NEA = Necessidade experiências adequadas ao desenvolvimento. 
Quadro 2. Continuação...

\begin{tabular}{|c|c|c|c|c|c|}
\hline $\begin{array}{l}\text { Código } \\
\text { do Artigo }\end{array}$ & Objetivo & Tipo de Estudo & Amostra & Contexto & $\begin{array}{l}\text { Necessidades } \\
\text { essenciais* } \\
\text { relacionadas } \\
\text { aos cuidados } \\
\text { descritos }\end{array}$ \\
\hline $\mathrm{A} 15^{30}$ & $\begin{array}{l}\text { Identificar as experiências } \\
\text { e obstáculos durante a } \\
\text { internação e após a alta dos } \\
\text { pais e mães de bebês que } \\
\text { participaram ou não de um } \\
\text { programa de alta precoce }\end{array}$ & Estudo qualitativo & 23 pais de RNPT & $\begin{array}{l}\text { Hospitalar e } \\
\text { Domiciliar }\end{array}$ & NPF \\
\hline $\mathrm{A} 16^{31}$ & $\begin{array}{l}\text { Determinar se os bebês } \\
\text { de pais que não falam a } \\
\text { língua inglesa receberam } \\
\text { atendimento ambulatorial } \\
\text { recomendado para cuidados } \\
\text { de acompanhamento para o } \\
\text { desenvolvimento neurológico }\end{array}$ & Estudo quantitativo & 1541 RNPT & Ambulatorial & NPF \\
\hline $\mathrm{A} 17^{32}$ & $\begin{array}{l}\text { Descrever a epidemiologia } \\
\text { e o tratamento do } \\
\text { refluxo gastroesofágico } \\
\text { medicamentoso no primeiro } \\
\text { ano de vida }\end{array}$ & $\begin{array}{l}\text { Estudo quantitativo } \\
\text { (estudo de coorte } \\
\text { retrospectivo) }\end{array}$ & 2217 RNPT & Ambulatorial & NPF \\
\hline $\mathrm{A} 18^{33}$ & $\begin{array}{c}\text { Descrever variáveis } \\
\text { antropométricas de RNPT } \\
\text { de Muito Baixo Peso em } \\
\text { acompanhamento de followup }\end{array}$ & $\begin{array}{l}\text { Estudo quantitativo } \\
\text { (observacional } \\
\text { longitudinal e } \\
\text { retrospectivo) }\end{array}$ & $\begin{array}{l}71 \text { crianças } \\
\text { egressas da UTIN, } \\
\text { com peso menor } \\
\text { de } 1.500 \mathrm{~g}\end{array}$ & Ambulatorial & NPF \\
\hline A19 14 & $\begin{array}{c}\text { Descrever as ações de } \\
\text { Enfermagem implementadas } \\
\text { no contexto domiciliar, a partir } \\
\text { das necessidades apresentadas } \\
\text { pelas famílias de bebês } \\
\text { nascidos muito baixo peso }\end{array}$ & $\begin{array}{l}\text { Estudo qualitativo } \\
\text { (convergente } \\
\text { assistencial) }\end{array}$ & $\begin{array}{l}09 \text { famílias de } \\
\text { RNPT }\end{array}$ & Domiciliar & NPF \\
\hline $\mathrm{A} 20^{34}$ & $\begin{array}{l}\text { Demonstrar que RNPT } \\
\text { assistidos por internação } \\
\text { domiciliar ganham mais } \\
\text { peso, comparados àqueles } \\
\text { internados em hospital }\end{array}$ & $\begin{array}{l}\text { Estudo quantitativo } \\
\text { (transversal) }\end{array}$ & $\begin{array}{l}130 \text { RNPT com } \\
\text { peso de alta } \\
\text { menor que } 2100 \mathrm{~g}\end{array}$ & $\begin{array}{l}\text { Hospitalar e } \\
\text { Domiciliar }\end{array}$ & NPF \\
\hline$A 21^{35}$ & $\begin{array}{l}\text { Determinar fatores preditores } \\
\text { maternos e infantis para } \\
\text { participação no programa de } \\
\text { seguimento }\end{array}$ & $\begin{array}{l}\text { Estudo quantitativo } \\
\text { (longitudinal) }\end{array}$ & $\begin{array}{l}1357 \text { mães de } \\
\text { RNPT }\end{array}$ & $\begin{array}{l}\text { Hospitalar e } \\
\text { Ambulatorial }\end{array}$ & NPF \\
\hline
\end{tabular}

Fonte: Dados da Pesquisa, 2020. *Legenda. Códigos atribuídos às necessidades essenciais: NPF = Necessidade de Proteção Física Segurança e Regulamentação; NCE = Necessidades de comunidades estáveis, amparadoras e de continuidade cultural; NRS = Necessidade de relacionamentos sustentadores contínuos; $\mathrm{NEI}=$ Necessidades de experiências que respeitem as diferenças individuais; NEA = Necessidade experiências adequadas ao desenvolvimento.

não foram incluídos, entretanto quanto aos estudos longitudinais que iniciaram a coleta dos dados na UTIN e continuaram após a alta hospitalar, compuseram a amostra desta revisão.

Em relação ao conceito ações de cuidado ao prematuro após a alta hospitalar, 14 estudos ${ }^{14,17,18,20-22,25-31,34}$ apresentaram ações de cuidado das quais foram identificadas o atendimento a mais de uma necessidade essencial. Sete estudos ${ }^{16,17,19,23,24,32,33,35}$ revelaram ações de cuidado para o atendimento de apenas uma necessidade essencial.
A Figura 2 apresenta um mapa do quantitativo de artigos nos quais foram identificadas ações correspondentes a cada uma das necessidades essenciais.

No processo de análise, foi possível codificar as ações de cuidados identificadas a partir das necessidades essenciais, tanto as ações realizadas pelos familiares, quanto àquelas realizadas nos serviços de saúde, no acompanhamento das crianças. O Quadro 3 apresenta as ações de cuidado identificadas, relacionadas a cada necessidade essencial. 


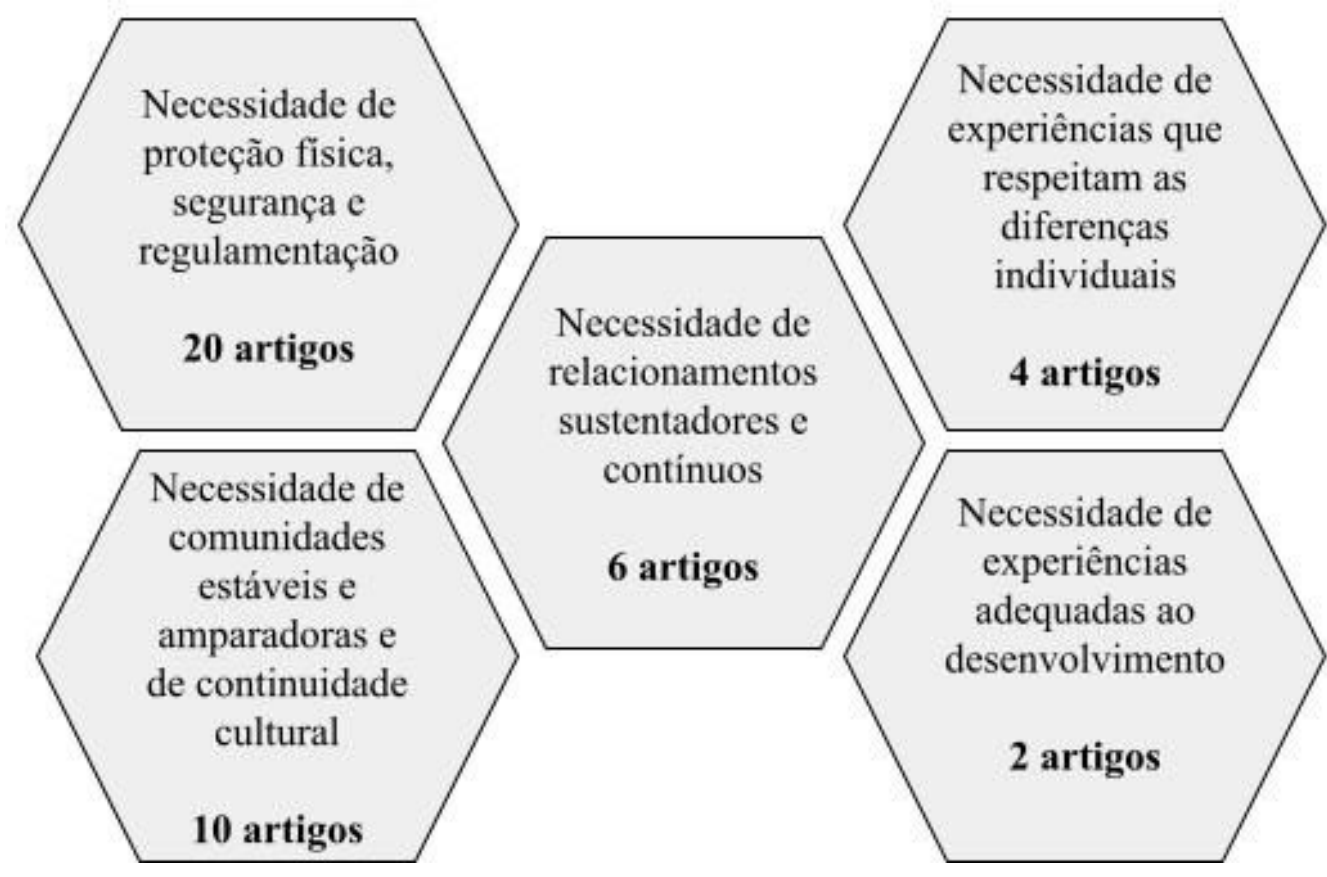

Figura 2. Mapa da distribuição dos estudos da revisão que descrevem ações relacionadas a cada uma das necessidades essenciais. Belo Horizonte, MG, Brasil, 2020.

Fonte: Dados da Pesquisa, 2020.

Quadro 3. Identificação das ações de cuidado e das necessidades essenciais. Belo Horizonte, MG, Brasil, 2020.

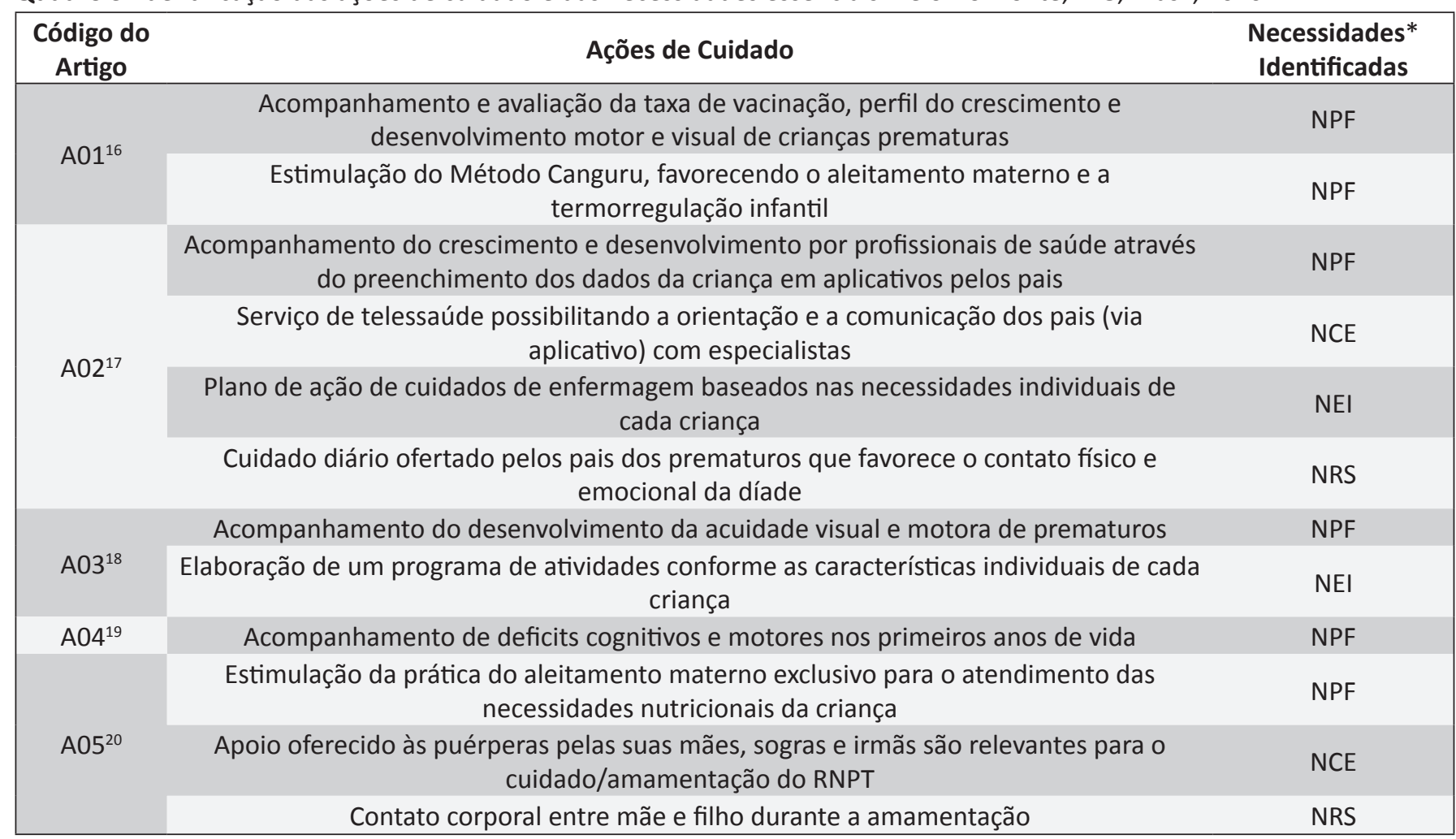

Fonte: Dados da Pesquisa, 2020. * Legenda. Códigos atribuídos às necessidades essenciais: NPF = Necessidade de Proteção Física Segurança e Regulamentação; NCE = Necessidades de comunidades estáveis, amparadoras e de continuidade cultural; NRS = Necessidade de relacionamentos sustentadores contínuos; NEI = Necessidades de experiências que respeitem as diferenças individuais; NEA = Necessidade experiências adequadas ao desenvolvimento. 
Quadro 3. Continuação...

\begin{tabular}{|c|c|c|}
\hline $\begin{array}{l}\text { Código do } \\
\text { Artigo }\end{array}$ & Ações de Cuidado & $\begin{array}{l}\text { Necessidades* } \\
\text { Identificadas }\end{array}$ \\
\hline \multirow{4}{*}{$A 06^{21}$} & $\begin{array}{l}\text { Ensino e orientação das famílias, pelas enfermeiras, acerca de cuidados cotidianos com } \\
\text { os filhos (trocar fraldas, dar banho, cuidados com o posicionamento, cólicas) }\end{array}$ & NPF \\
\hline & $\begin{array}{l}\text { Aprendizado dos pais com a enfermeira sobre os cuidados do filho durante o período de } \\
\text { internação hospitalar, aumentando a segurança deles para cuidar }\end{array}$ & NCE \\
\hline & Participação do pai nas tarefas domésticas favorecendo o vínculo da mãe com o filho & NRS \\
\hline & $\begin{array}{c}\text { Aprendizado com as enfermeiras sobre o conforto e aconchego do filho, aumentando a } \\
\text { proximidade da díade }\end{array}$ & NRS \\
\hline \multirow{2}{*}{$\mathrm{A} 07^{22}$} & $\begin{array}{l}\text { Orientação e intervenção das avós de prematuros na amamentação exclusiva com uso de } \\
\text { chás, ervas medicinais e alimentação complementar logo após a ida para o domicílio }\end{array}$ & NPF \\
\hline & $\begin{array}{l}\text { Realização dos cuidados no tratamento de prematuros doentes pelas avós, na } \\
\text { comunidade, após a alta hospitalar }\end{array}$ & NCE \\
\hline $\mathrm{A} 08^{23}$ & $\begin{array}{l}\text { Acompanhamento sistemático das crianças por serviços de saúde contemplando as } \\
\text { questões físicas, comportamentais e ambientais }\end{array}$ & NPF \\
\hline$A 09^{24}$ & $\begin{array}{l}\text { Visita hospitalar pelos profissionais de saúde da atenção básica, visando à criação de } \\
\text { vínculo com a família e a maior possibilidade de um acompanhamento pós alta }\end{array}$ & NCE \\
\hline \multirow{3}{*}{$\mathrm{A} 10^{25}$} & Avaliação do desenvolvimento motor, cognitivo no primeiro ano de vida & NPF \\
\hline & $\begin{array}{l}\text { Ensino às famílias sobre posicionamentos e atividades motoras que pudessem favorecer } \\
\text { o desenvolvimento neuromotor dos prematuros }\end{array}$ & NEA \\
\hline & $\begin{array}{c}\text { Intervenção fisioterápica centrada na família com orientações acerca do holding e do } \\
\text { cuidado }\end{array}$ & NRS \\
\hline \multirow{2}{*}{$\mathrm{A} 11^{26}$} & $\begin{array}{c}\text { Orientações aos familiares sobre a importância de levarem seus filhos prematuros } \\
\text { para o acompanhamento do crescimento e desenvolvimento em um ambulatório de } \\
\text { seguimento }\end{array}$ & NPF \\
\hline & $\begin{array}{l}\text { Acompanhamento de lactentes nascidos prematuros por fisioterapeutas, em um } \\
\text { ambulatório de followup, orientando intervenções precoces para favorecer o } \\
\text { desenvolvimento neuromotor para serem realizadas no domicílio pelos familiares }\end{array}$ & NEA \\
\hline \multirow[b]{2}{*}{$\mathrm{A} 12^{27}$} & Acompanhamento do desenvolvimento da acuidade visual e motora de prematuros & NPF \\
\hline & $\begin{array}{c}\text { Elaboração de um programa de atividades conforme as características individuais de cada } \\
\text { criança }\end{array}$ & NEI \\
\hline \multirow{2}{*}{$\mathrm{A} 13^{28}$} & $\begin{array}{l}\text { Abordagem da família pelos profissionais de saúde e discussão acerca do tipo de } \\
\text { alimentação da criança }\end{array}$ & NPF \\
\hline & $\begin{array}{c}\text { Permanência das mães em tempo integral com seus filhos após a alta hospitalar e } \\
\text { participação do pai nos cuidados às crianças }\end{array}$ & NRS \\
\hline \multirow{5}{*}{$\mathrm{A} 14^{29}$} & $\begin{array}{c}\text { Reconhecimento, pelas mães, dos sinais de risco e perigo a partir de orientações da } \\
\text { equipe de saúde }\end{array}$ & NPF \\
\hline & $\begin{array}{l}\text { Conduta de profissionais de saúde baseadas em protocolos e checklists. Necessidade de } \\
\text { melhorar o cuidado individualizado e ações que possam incentivar a confiança ao invés } \\
\text { do amedrontamento das mães. }\end{array}$ & NPF \\
\hline & Troca de experiências com outras mães sobre os cuidados do bebê & NCE \\
\hline & $\begin{array}{l}\text { Convivência das mães com seus filhos no domicílio favorece o reconhecimento das } \\
\text { necessidades individuais de sua criança }\end{array}$ & NEI \\
\hline & $\begin{array}{c}\text { Busca das mães por proximidade e fortalecimento do vínculo com seus filhos durante a } \\
\text { internação na UTIN gerando autenticidade e plenitude materna }\end{array}$ & NRS \\
\hline \multirow{2}{*}{$\mathrm{A} 15^{30}$} & $\begin{array}{c}\text { Orientações pela enfermeira sobre os cuidados do RNPT em casa como o banho e o ritmo } \\
\text { de sono }\end{array}$ & NPF \\
\hline & $\begin{array}{c}\text { Orientações realizadas por enfermeira sobre os cuidados do RNPT em casa resultando em } \\
\text { segurança e tranquilidade aos pais }\end{array}$ & NCE \\
\hline
\end{tabular}

Fonte: Dados da Pesquisa, 2020. *Legenda. Códigos atribuídos às necessidades essenciais: NPF = Necessidade de Proteção Física Segurança e Regulamentação; $\mathrm{NCE}=$ Necessidades de comunidades estáveis, amparadoras e de continuidade cultural; NRS = Necessidade de relacionamentos sustentadores contínuos; NEI = Necessidades de experiências que respeitem as diferenças individuais; NEA = Necessidade experiências adequadas ao desenvolvimento. 
Quadro 3. Continuação...

\begin{tabular}{|c|c|c|}
\hline $\begin{array}{l}\text { Código do } \\
\text { Artigo }\end{array}$ & Ações de Cuidado & $\begin{array}{l}\text { Necessidades* } \\
\text { Identificadas }\end{array}$ \\
\hline \multirow{3}{*}{$\mathrm{A} 16^{31}$} & Atendimento nos primeiros sete dias após a alta & NPF \\
\hline & Realização e acompanhamento da situação vacinal. & NPF \\
\hline & $\begin{array}{l}\text { Acompanhamento pós-alta, em nível ambulatorial, favorecendo a adaptação da língua e } \\
\text { da cultura }\end{array}$ & NCE \\
\hline $\mathrm{A} 17^{32}$ & $\begin{array}{l}\text { Uso criterioso da prescrição de medicamentos para refluxo gastroesofágico em } \\
\text { prematuros devido às complicações advindas da terapêutica e da incerteza da eficácia no } \\
\text { tratamento }\end{array}$ & NPF \\
\hline \multirow{2}{*}{$\mathrm{A} 18^{33}$} & $\begin{array}{l}\text { Comparação do crescimento e do tipo de alimentação da criança à alta hospitalar e aos } \\
\qquad 12 \text { meses de idade }\end{array}$ & NPF \\
\hline & $\begin{array}{l}\text { Abordagem e discussão sobre o tipo de alimentação da criança e dos scores de } \\
\text { crescimento junto às famílias no seguimento ambulatorial }\end{array}$ & NPF \\
\hline \multirow{2}{*}{$\mathrm{A} 19^{14}$} & $\begin{array}{l}\text { Orientação aos pais e entrega de folhetos explicativos, realizadas pelos enfermeiros, } \\
\text { sobre a prevenção de agravos e promoção da saúde }\end{array}$ & NPF \\
\hline & $\begin{array}{c}\text { Visita domiciliar pelos enfermeiros para orientar sobre os cuidados do prematuro } \\
\text { minimizando o medo e a ansiedade dos pais }\end{array}$ & NCE \\
\hline \multirow{3}{*}{$\mathrm{A} 20^{34}$} & Abordagem e discussão sobre o tipo de alimentação da criança & NPF \\
\hline & $\begin{array}{l}\text { Distribuição de cartilhas informativas para os pais pelos profissionais, sobre o ganho } \\
\text { ponderal, vacinação, morte súbita, sono }\end{array}$ & NPF \\
\hline & $\begin{array}{c}\text { Contato telefônico, com os profissionais de saúde, acessível aos pais } 24 \text { horas/dia, para } \\
\text { tirar dúvidas e receber suporte para o cuidado }\end{array}$ & NCE \\
\hline $\mathrm{A} 21^{35}$ & $\begin{array}{c}\text { Realização consultas de acompanhamento do crescimento e desenvolvimento em } \\
\text { ambulatório de followup para egressos de alto risco da UTIN }\end{array}$ & NPF \\
\hline
\end{tabular}

Fonte: Dados da Pesquisa, 2020. *Legenda. Códigos atribuídos às necessidades essenciais: NPF = Necessidade de Proteção Física Segurança e Regulamentação; NCE = Necessidades de comunidades estáveis, amparadoras e de continuidade cultural; NRS = Necessidade de relacionamentos sustentadores contínuos; NEI = Necessidades de experiências que respeitem as diferenças individuais; NEA = Necessidade experiências adequadas ao desenvolvimento.

\section{DISCUSSÃO}

Embora os estudos incluídos nesta revisão tenham evidenciado ações de cuidado que podem contribuir para o atendimento das necessidades essenciais, nenhum deles utilizou-se de qualquer referencial de necessidades. A ausência de um referencial que oriente a seleção de cuidados pode levar a planos limitados, em vez de orientados pelo raciocínio crítico e de um cuidado integral ${ }^{36}$.

A necessidade de proteção física, segurança e regulamentação pode ser atendida por: avaliações periódicas dos recém-nascidos permitindo a identificação precoce de transtornos e dificuldades, orientações às suas famílias sobre o crescimento e o desenvolvimento infantil. Cuidados ambientais para a proteção da saúde física das crianças são fundamentais para o atendimento dessa necessidade ${ }^{1}$. O conjunto de ações apresentados pela literatura que compõem essa necessidade incluiu: ações promotoras do desenvolvimento motor ${ }^{16,18,19,25,27}$, de linguagem, cognitivo e visual|16,18,19,25,27; orientações sobre os cuidados cotidianos no domicílio, favorecedores do crescimento e desenvolvimento ${ }^{17,21,30,32}$; orientações às famílias quanto aos sinais de perigo ${ }^{29}$; a prevenção de agravos e infecções ${ }^{14,31,34}$; orientações sobre a necessidade de realização do acompanhamento de crescimento e desenvolvimento ${ }^{17,19,23,26,27,33,35}$

As ações de cuidado favorecedoras de proteção física, segurança e regulamentação prevaleceram como sendo a necessidade mais presente nesta revisão e, isto pode estar relacionado ao modelo de atenção à saúde predominante na assistência ao prematuro após a alta hospitalar. Nos serviços de saúde da APS, ainda prevalece o atendimento biologicista, centrado na doença e que não é capaz de ofertar um cuidado que atenda integralmente às necessidades de saúde das crianças ${ }^{37}$.

É preciso reconhecer, ao adotarmos uma perspectiva integral da atenção, que o cuidado à criança nascida prematura e sua família após a alta hospitalar deve incorporar práticas capazes de potencializar a produção da vida e nessa construção não devemos atender, exclusivamente, as demandas biológicas do prematuro, mas também considerar os projetos existenciais das famílias ${ }^{4}$.

Uma das estratégias de apoio às famílias é seu preparo para o cuidado do prematuro egresso da UTIN. Tal preparo é importante, visto que auxilia não apenas à aprendizagem acerca de cuidados diários que busquem a proteção física dessas crianças, mas também promove o bem-estar psicológico dos pais e gera sentimentos de segurança e confiança para o cuidado domiciliar ${ }^{38}$. Nesse contexto, os profissionais de saúde atuam como os protagonistas, preparando as famílias por meio do oferecimento de cartilhas educativas e de orientações por telefone ${ }^{39}$, ações também evidenciadas pelos achados desta revisão.

A necessidade de comunidades estáveis, amparadoras e de continuidade cultural é descrita como aquela na qual as 
comunidades e culturas fornecem o contexto ou a estrutura para as outras necessidades essenciais. Ressalta-se que os profissionais e serviços de saúde compõem a comunidade amparadora ${ }^{1}$. Ações que parecem contribuir para o atendimento a essa necessidade são aquelas relacionadas à continuidade do cuidado do prematuro após a alta hospitalar em serviços de saúde como as Unidades Básicas e os Ambulatórios de Seguimento ${ }^{23,31}$, ao cuidado pela família no domicílio assegurando corresponsabilidade ${ }^{20,22}$, na perspectiva da sustentabilidade da saúde da criança e também ao uso de tecnologia como ferramenta favorecedora da comunicação entre a família e os profissionais de saúde ${ }^{17}$.

O acompanhamento de crianças prematuras após a alta hospitalar pode apresentar-se como uma estratégia assistencial favorecedora de comunidades amparadoras, desde que sejam implementadas intervenções que atendam às necessidades singulares de cada família. Para isso, faz-se necessária a construção de um diálogo acolhedor e resolutivo que resulte na construção de vínculo entre os profissionais e os cuidadores desses prematuros ${ }^{4}$.

O destaque para as ações de cuidado que resultam na estabilidade e continuidade cultural em uma comunidade foi identificado em um estudo ${ }^{22}$ no qual as avós paternas são as principais cuidadoras de prematuros após receberem alta hospitalar. O universo familiar e as suas práticas culturais que, muitas vezes, se manifestam como contribuições de familiares ao cuidado da criança prematura influenciando as gerações deve ser compreendido e respeitado, pois cada organização familiar elabora suas concepções próprias, com significados únicos e especiais dentro da sua comunidade ${ }^{40}$.

A comunidade amparadora, estável e de continuidade cultural como uma necessidade essencial ao desenvolvimento da criança em seu potencial, ainda é um desafio a ser superado no contexto de vida de prematuros e de suas famílias. Ações de cuidado profissionais centradas na dimensão biológica podem ser indicativos da necessidade de avanço para contemplar a comunidade amparadora.

A necessidade de relacionamentos sustentadores contínuos é importante para o desenvolvimento de saúde física, emocional, social e intelectual. As crianças necessitam de cuidado sensível e sustentador para desenvolverem capacidades de segurança, empatia e compaixão'1.

Nesta revisão, foram identificadas ações nessa dimensão, a saber: ações que favoreçam a permanência em tempo integral da família para a participação no cuidado de seus filhos prematuros durante a internação e após a alta, no domicílio; intervenções centradas na família e que possibilitem a prática da amamentação exclusiva.

$\mathrm{O}$ ato de amamentar envolve a aproximação da mãe e do recém-nascido levando à criação de vínculo entre eles. $O$ contato físico entre ambos, durante o ato de amamentar, se repete, continuamente, por um período regular. Esse contato íntimo, frequente e prolongado resulta na formação e no fortalecimento afetivo entre mãe e filho. Isso pode gerar maior compreensão da mulher sobre as necessidades de seu recém-nascido e favorecer a vivência da maternidade ${ }^{41}$.
A permanência e a participação dos pais de prematuros no cuidado de seus filhos durante a internação na UTIN e o preparo para o pós-alta podem ser consideradas ações favorecedoras do apego entre eles. O cuidado do prematuro no domicílio demanda o empreendimento de um ritmo diário e pode ser mais bem atendido quando realizado por um cuidador apegado e que apresenta disponibilidade interna para cuidar, favorecendo ao atendimento à necessidade de relacionamentos sustentáveis e contínuos.

Os achados desta revisão revelam ações presentes na assistência em saúde a prematuros que são favorecedoras do apego e, portanto, podem sinalizar um potencial atendimento à necessidade de relacionamentos sustentadores e contínuos.

A necessidade de experiências que respeitem as diferenças individuais está relacionada à capacidade de reconhecer a singularidade de cada criança a partir de suas características genéticas, hereditárias e da sua forma de agir, pensar e se comportar socialmente para que possam ser oferecidos cuidados individualizados, a fim de que ela possa desfrutar de seu potencial singular e se desenvolver a partir de seus pontos fortes ${ }^{1}$.

Ações profissionais pautadas pela integralidade do cuidado como: o respeito a autonomia e sensibilidade materna; reconhecimento dos aspectos singulares de cada família e de cada criança, conforme suas características individuais, atitudes de reconhecimento das fortalezas e do potencial de seus filhos pelas famílias são achados desta revisão que podem contribuir para o atendimento dessa necessidade.

Para o atendimento dessa necessidade essencial, a integralidade da assistência de enfermagem deve contemplar o atendimento às demandas de cuidados das crianças no domicílio de forma singular. Para isso, a enfermeira deve oferecer uma assistência com vistas a promover o bem-estar das famílias de modo a atendê-las de acordo com as necessidades individuais ${ }^{42}$.

Embora a necessidade de experiências que respeitem as diferenças individuais seja ancorada em aspectos como o temperamento, habilidades físicas e sensoriais das crianças, as ações de cuidado identificadas na literatura para o atendimento a essa necessidade foram mais encontradas em estudos, cujos participantes foram as famílias e não os prematuros. Esse achado pode estar relacionado à faixa etária dos prematuros incluídos nesta revisão. Nessa fase de lactentes, as percepções acerca das habilidades físicas e comportamentais dos filhos ainda são sob a ótica de seus pais.

A necessidade de experiências adequadas ao desenvolvimento refere-se a experiências favorecedoras do desenvolvimento da inteligência, moralidade, saúde emocional e habilidades acadêmicas ${ }^{1}$.

Nesta revisão, identificamos ações que preparam a família para o cuidado no domicílio com vistas ao atendimento das demandas de cuidados promotoras do desenvolvimento neuromotor da criança nascida prematura. Além da família, os profissionais de saúde também aparecem como protagonistas de cuidados para promoverem experiências adequadas ao desenvolvimento durante as intervenções em ambulatórios de seguimento.

Uma metanálise com objetivo de avaliar os efeitos de um programa de intervenção precoce com foco na família, na 
promoção do desenvolvimento cognitivo, motor e de linguagem no primeiro ano de vida de crianças expostas a prematuridade e/ou risco social, evidenciou que intervenções em grupos, em ambiente ambulatorial, trouxe benefícios relevantes para o desenvolvimento da linguagem receptiva de crianças nascidas prematuras e de famílias de baixa renda ${ }^{43}$.

Não foram identificadas ações de cuidado potencialmente favoráveis ao atendimento à necessidade do estabelecimento de limites, organização e expectativas. Descrita como aquela na qual, para viver em sociedade, todas as crianças precisam aprender a respeitarem regras de convívio social por meio da educação. Contempla o equilíbrio dos limites interno e externo possibilitando também o exercício da empatia ${ }^{1}$. Esse resultado pode estar relacionado ao fato de que o comportamento socialmente aceito é esperado ao final da primeira infância ${ }^{44} \mathrm{e}$ não no período de vida do prematuro logo após a alta hospitalar.

Entretanto, é preciso considerar que, em uma perspectiva de cuidado integral à saúde das crianças, é oportuna uma abordagem junto às famílias sobre como elas pretendem educar seus filhos, se é a partir de uma perspectiva baseada no afeto ou no castigo, para que possamos contemplar outras dimensões do cuidado ao prematuro que não apenas a biológica. A discussão sobre as práticas parentais é relevante como um caminho a ser trilhado para educação social da criança. Em concordância com o referencial de necessidades essenciais há evidências de que o estilo de autoridade favorece o desenvolvimento do autocontrole e da autonomia, habilidades necessárias ao convívio social ${ }^{45}$. Por outro lado, práticas coercitivas são deletérias para o desenvolvimento infantil e comportamento social ${ }^{46}$.

As fortalezas desta revisão foram: a variedade de países onde foram realizados os estudos originais, as diferentes populações de prematuros, familiares e profissionais de saúde. A diversidade de abordagens qualitativas e quantitativas; embora não tenham sido identificados estudos de métodos mistos. O contexto também foi diversificado e contemplando os diferentes lócus de cuidado.

No entanto, reconhecem-se algumas limitações nesse processo, pois há pesquisas publicadas em outros idiomas que não foram incluídas, bem como não se considerou uma diversidade de estudos que provavelmente existam em outras bases de indexação. Além disso, o modelo das necessidades essenciais das crianças foi elaborado para o público infantil, porém não é específico para aquelas nascidas prematuras.

\section{CONSIDERAÇÕES FINAIS E CONTRIBUIÇÕES PARA A PRÁTICA}

Os resultados encontrados nesta revisão evidenciaram que as ações de cuidado contemplam, principalmente, a dimensão física, no entanto ao considerar o cuidado integral, ainda são necessários avanços nas ações para o atendimento de outras dimensões como a emocional e a social. Analisar as ações de cuidado às crianças nascidas prematuras após a ida para o domicílio, a partir do referencial das necessidades essenciais, permitiram identificar lacunas no conhecimento que podem desencadear pesquisas de enfermagem como, por exemplo, estudos que discutam sobre ações de cuidado para o atendimento à necessidade de estabelecimento de limites, organização e expectativas devido à sua particularidade no campo da saúde da criança nascida prematura.

Aponta-se também a necessidade de investimento em estudos acerca de como os cuidadores familiares e profissionais de saúde podem identificar e agir de maneira a reconhecer a personalidade e o temperamento de cada criança para oferecer a ela um cuidado singular, atendendo à necessidade de experiências que respeitem as suas diferenças individuais. É preciso também a produção de evidências sobre ações de cuidado aos prematuros após a alta hospitalar na perspectiva da humanização e da integralidade do cuidado para que as necessidades essenciais das crianças sejam contempladas para promover o desenvolvimento de cada uma delas em todo o seu potencial.

Acreditamos que as evidências deste artigo sobre as ações de cuidado que atendem ou não às necessidades das crianças nascidas prematuras, poderá nortear profissionais e gestores de saúde para a manutenção, implementação e qualificação do cuidado direcionado à criança nascida prematura e sua família.

\section{CONTRIBUIÇÕES DOS AUTORES}

Concepção e desenho da revisão. Cynthia Márcia Romano Faria Walty. Elysângela Dittz Duarte. Maria de La Ó Ramallo Veríssimo. Patrícia Pinto Braga.

Levantamento e busca bibliográfica da revisão. Cynthia Márcia Romano Faria Walty. Elysângela Dittz Duarte. Nayara Luiza Henriques. Natália de Mesquita Melo Coimbra

Análise dos dados. Cynthia Márcia Romano Faria Walty. Nayara Luiza Henriques. Natália de Mesquita Melo Coimbra. Patrícia Pinto Braga. Elysângela Dittz Duarte

Interpretação dos dados. Cynthia Márcia Romano Faria Walty. Nayara Luiza Henriques. Natália de Mesquita Melo Coimbra. Patrícia Pinto Braga. Maria de La Ó Ramallo Veríssimo. Elysângela Dittz Duarte

Redação e revisão crítica do manuscrito. Cynthia Márcia Romano Faria Walty. Nayara Luiza Henriques. Natália de Mesquita Melo Coimbra. Patrícia Pinto Braga. Maria de La Ó Ramallo Veríssimo. Elysângela Dittz Duarte

Aprovação da versão final do artigo. Cynthia Márcia Romano Faria Walty. Nayara Luiza Henriques. Natália de Mesquita Melo Coimbra. Patrícia Pinto Braga. Maria de La Ó Ramallo Veríssimo. Elysângela Dittz Duarte

Responsabilidade por todos os aspectos do conteúdo e a integridade do artigo publicado. Cynthia Márcia Romano Faria Walty. Nayara Luiza Henriques. Natália de Mesquita Melo Coimbra. Patrícia Pinto Braga. Maria de La Ó Ramallo Veríssimo. Elysângela Dittz Duarte

\section{EDITOR ASSOCIADO}

Eliane Tatsch Neves (1) 


\section{EDITOR CIENTÍFICO}

\author{
Ivone Evangelista Cabral (10)
}

\section{REFERÊNCIAS}

1. Brazelton TB, Greespan SI. As necessidades essenciais das crianças: o que toda criança precisa para crescer, aprender e se desenvolver. Porto Alegre: Artmed; 2002.

2. Lee SK, Beltempo M, McMillan DD, Seshia M, Singhal N, Dow K et al. Outcomes and care practices for preterm infants born at less than 33 weeks' gestation: a quality-improvement study. CMAJ. 2020;192(4):E8191. http://dx.doi.org/10.1503/cmaj.190940. PMid:31988152.

3. Del Pino M, Nieto R, Meritano J, Rabosto Moleon R, Orden AB, Villafañe L et al. Recomendaciones para la evaluación del tamaño al nacer y del crecimiento posnatal de los recién nacidos prematuros. Arch Argent Pediatr. 2020;118(5):S142. http://dx.doi.org/10.5546/aap.2020.S142. PMid:32924411.

4. Braga PP, Sena RR. Devir cuidadora de prematuro e os dispositivos constituintes da continuidade da atenção pós-alta. Texto Contexto Enferm. 2017;26(3):1-8. http://dx.doi.org/10.1590/0104-07072017003070016.

5. Lapillonne A, Bronsky J, Campoy C, Embleton N, Fewtrell M, Fidler Mis $\mathrm{N}$ et al. Feeding the late and moderately preterm infant: a position paper of the European Society for Paediatric Gastroenterology, Hepatology and Nutrition Committee on nutrition. J Pediatr Gastroenterol Nutr. 2019;69(2):259-70. http://dx.doi.org/10.1097/MPG.0000000000002397. PMid:31095091.

6. Baldassarre ME, Giannì ML, Di Mauro A, Mosca F, Laforgia N. Complementary feeding in preterm infants: where do we stand? Nutrients. 2020;12(5):1251-9. http://dx.doi.org/10.3390/nu12051259. PMid:32365485

7. Veríssimo MÓR. The irreducible needs of children for development: a frame of reference to health care. Rev Esc Enferm USP. 2017;51:e03283. http://dx.doi.org/10.1590/s1980-220x2017017403283. PMid:29562042.

8. de Mello DF, Henrique NC, Pancieri L, Veríssimo ML, Tonete VL, Malone M. Child safe from the perspective of essencial needs. Rev Lat Am Enfermagem. 2014;22(4):604-10. http://dx.doi.org/10.1590/01041169.3651.2458. PMid:25296144.

9. Aromataris E, Munn Z, editors. JBI Manual for Evidence Synthesis. JBI. 2020. https://doi.org/10.46658/JBIMES-20-01.

10. Tricco AC, Lillie E, Zarin W, O'Brien KK, Colquhoun $\mathrm{H}$, Levac $\mathrm{D}$, et al. PRISMA extension for scoping reviews (PRISMA-ScR): checklist and explanation. Ann Intern Med. 2018;169(7):467-73. http://dx.doi. org/10.7326/M18-0850.

11. Arksey H, O'Malley L. Scoping studies: towards a methodological framework. Int J Soc Res Methodol. 2005;8(1):19-32. http://dx.doi.org /10.1080/1364557032000119616.

12. Ouzzani M, Hammady H, Fedorowicz Z, Elmagarmid A. Rayyan - a web and mobile app for systematic reviews. Syst Rev. 2016;5(1):210. http://dx.doi.org/10.1186/s13643-016-0384-4. PMid:27919275.

13. Hsieh HF, Shannon SE. Three approaches to qualitative content analysis. Qual Health Res. 2005;15(9):1277-88. http://dx.doi. org/10.1177/1049732305276687. PMid:16204405.

14. Sassá AH, Gaíva MAM, Higarashi IH, Marcon SS. Ações de enfermagem na assistência domiciliar ao recém-nascido de muito baixo peso. Acta Paul Enferm. 2014;27(5):492-8. http://dx.doi.org/10.1590/19820194201400080.

15. MAXQDA. Software VERBI. MAXQDA 2020 [software de computador]. Berlim, Alemanha:VERBI Software; 2020 [citado 2020 Jul 27]. Disponível em: http://www.maxqda.com

16. Montealegre-Pomar A, Sierra-Andrade AP, Charpak N. El Programa Madre Canguro de Yopal, Colombia: una oportunidad de seguimiento del niño prematuro. Rev Salud Publica (Bogota). 2018;20(1):10-6. http:// dx.doi.org/10.15446/rsap.v20n1.67974. PMid:30183879.

17. Garne Holm K, Brødsgaard A, Zachariassen G, Smith AC, Clemensen J. Parent perspectives of neonatal tele-homecare: a qualitative study. JTelemed Telecare. 2019;25(4):221-9. http://dx.doi.org/10.1177/1357633X18765059. PMid:29792079.
18. Sgandurra G, Lorentzen J, Inguaggiato E, Bartalena L, Beani E, Cecchi $F$ et al. A randomized clinical trial in preterm infants on the effects of a home-based early intervention with the'CareToy System'. PLoS One. 2017;12(3):e0173521. http://dx.doi.org/10.1371/journal.pone.0173521. PMid:28328946.

19. Nwabara O, Rogers C, Inder T, Pineda R. Early therapy services following neonatal intensive care unit discharge. Phys Occup Ther Pediatras. 2017;37(4):414-24. http://dx.doi.org/10.1080/01942638.2016.12479 37. PMid:27967287.

20. Walty CMRF, Duarte ED. O aleitamento materno de recém-nascidos prematuros após a alta hospitalar. Rev Enferm Cent Oeste Min 2017;7:e1689 http://dx.doi.org/10.19175/recom.v7i0.1689.

21. Zani AV, Silva TR, Parada CMGL. The early days of the premature child at home: collective subject discourse. Online Braz J Nurs. [Internet]. 2017 [citado 2020 jul 30];16(1):48-56. Disponível em: http://www.objnursing. uff.br/index.php/nursing/article/view/5555

22. Adama EA, Bayes S, Sundin D. Parents' experiences of caring for preterm infants after discharge with grandmothers as their main support. J Clin Nurs. 2017;27(17-18):3377-86. http://dx.doi.org/10.1111/jocn.13868. PMid:28474752.

23. Andersson AK, Martin L, Strand Brodd K, Almqvist L. Patterns of everyday functioning in preschool children born preterm and at term. Res Dev Disabil. 2017;67:82-93. http://dx.doi.org/10.1016/j.ridd.2017.06.005. PMid:28651224.

24. Aires LCP, Santos EKA, Bruggemann OM, Backes MTS, Costa R Referência e contrarreferência do bebê egresso da unidade neonatal no sistema de saúde: percepção de profissionais de saúde da Atenção Primária. Esc Anna Nery Rev Enferm. 2017;21(2). http://dx.doi. org/10.5935/1414-8145.20170028.

25. Elbasan B, Kocyigit MF, Soysal-Acar AS, Atalay Y, Gucuyener K. The effects of family-centered physiotherapy on the cognitive and motor performance in premature infants. Infant Behav Dev. 2017;49:214-9. http://dx.doi.org/10.1016/j.infbeh.2017.09.007. PMid:28957689.

26. Bivoleanu A, Avasiloaiei A, Moscalu M, Stamatin M. The role of followup in monitoring the outcomes of prematurity in a Cohort of Romanian Infants. Balkan Med J. 2017;34(1):21-7. http://dx.doi.org/10.4274/ balkanmedj.2015.1125. PMid:28251019.

27. Sgandurra G, Bartalena L, Cecchi F, Cioni G, Giampietri M, Greisen $G$ et al. A pilot study on early home-based intervention through an intelligent baby gym (CareToy) in preterm infants. Res Dev Disabil. 2016;53-54:32-42. http://dx.doi.org/10.1016/j.ridd.2016.01.013. PMid:26851385.

28. Sammy DM, Chege MN, Oyieke J. Early growth in preterm infants after hospital discharge in rural Kenya: longitudinal study. Pan Afr Med J. 2016;24:158. http://dx.doi.org/10.11604/pamj.2016.24.158.7795. PMid:27795756.

29. Custodio N, Marski BSL, Abreu FCP, Mello DF, Wernet M. Interações entre profissionais de saúde e mães de prematuros: influência no cuidado materno. Rev Enferm UERJ. 2016;24(1):11659. http://dx.doi. org/10.12957/reuerj.2016.11659.

30. Toral-López I, Fernández-Alcántara M, González-Carrión P, Cruz-Quintana F, Rivas-Campos A, Pérez-Marfil N. Needs perceived by parents of preterminfants: integratingcareintotheearlydischargeprocess. J Pediatr Nurs. 2016;31(2):e99-108. http://dx.doi.org/10.1016/j.pedn.2015.09.007. PMid:26497754.

31. Eneriz-Wiemer M, Saynina O, Sundaram V, Lee HC, Bhattacharya J, Sanders LM. Parent language: a predictor for neurodevelopmenta follow-up care among infants with very low birth weight. Acad Pediatr. 2016;16(7):645-52. http://dx.doi.org/10.1016/j.acap.2016.04.004 PMid:27130810.

32. D'Agostino JA, Passarella M, Martin AE, Lorch SA. Use of gastroesophagea reflux medications in premature infants after NICU discharge. Pediatrics. 2016;138(6):e20161977. http://dx.doi.org/10.1542/peds.2016-1977. PMid:27940703.

33. Rover MMS, Viera CS, Toso BRGO, Grassiolli S, Bugs BM. Growth of Very Low Birth Weight Preterm until 12 months of Corrected Age. J Hum Growth Dev. 2015;25(3):351-6. http://dx.doi.org/10.7322/jhgd.90228.

34. Alvarez Miró R, Lluch Canut MT, Figueras Aloy J, Esqué Ruiz MT, Arroyo Gili L, Bella Rodríguez J et al. Evolucióndel peso del prematuro con 
alta precoz y atención domiciliaria de enfermería. An Pediatr (Barc). 2014;81(6):352-9. http://dx.doi.org/10.1016/j.anpedi.2013.10.024. PMid:24582520.

35. Ballantyne M, Stevens B, Guttmann A, Willan AR, Rosenbaum P. Maternal and infant predictors of attendance at Neonatal Follow-Up programmes. Child Care Health Dev. 2014;40(2):250-8. http://dx.doi. org/10.1111/cch.12015. PMid:23294101.

36. Ribeiro O, Martins MMFPDS, Tronchin DMR, Silva JMAVD. Exercício profissional dos enfermeiros sustentado nos referenciais teóricos da disciplina: realidade ou utopia. Rev Enf Ref. 2018;4(19):39-48. http:// dx.doi.org/10.12707/RIV18040.

37. Damasceno SS, Nóbrega VM, Coutinho SED, Reichert APS, Toso BRGO, Collet N. Saúde da criança no Brasil: orientação da rede básica à Atenção Primária à Saúde. Cien Saude Colet. 2016;21(9):2961-73. http://dx.doi.org/10.1590/1413-81232015219.25002015. PMid:27653081.

38. Amorim M, Alves E, Kelly-Irving M, Ribeiro Al, Silva S. Quality of life of parents of very preterm infants 4 months after birth: a mixed methods study. Health Qual Life Outcomes. 2018;16(1):178. http://dx.doi. org/10.1186/s12955-018-1011-y. PMid:30200971.

39. Bedford ZC, Bench S. A review of interventions supporting parent's psychological well-being after a child's intensive care unit discharge. Nurs Crit Care. 2019;24(3):153-61. http://dx.doi.org/10.1111/nicc.12405 PMid:30537005.

40. Oliveira EAR, Rocha SS. O cuidado cultural às crianças na dinâmica familiar: reflexões para a Enfermagem. Rev Interdiscip. [Internet]. 2015 [citado 2020 jul 30];8(1):227-33. Disponível em: https://revistainterdisciplinar. uninovafapi.edu.br/index.php/revinter/article/view/302/pdf 198
41. Silva BAA, Braga LP. Fatores promotores do vínculo mãe-bebê no puerpério imediato hospitalar: uma revisão integrativa. Rev SBPH. [Internet]. 2019 [citado 2020 jul 31];22(1):258-79. Disponível em http://pepsic.bvsalud.org/scielo.php?script=sci_arttext\&pid=S151608582019000100014\&lng=pt

42. Tavares TS, Sena RR, Duarte ED. Implications for nursing care concerning children discharged from a neonatal unit with chronic conditions. Rev Rene. 2016;17(5):659-67. http://dx.doi.org/10.15253/21756783.2016000500011.

43. Ferreira RC, Alves CRL, Guimarães MAP, Menezes KKPD, Magalhães LDC. Effects of early interventions focused on the family in the development of children born preterm and/or at social risk: a meta-analysis. J Pediatr (Rio J). 2020;96(1):20-38. http://dx.doi.org/10.1016/j.jped.2019.05.002. PMid:31254528.

44. Silva TA, Cavalcante C, lêda L. Habilidades sociais infantis: comparações por gênero, idade e características escolares. Estud Pesqui Psicol. [Internet]. 2017 [citado 2020 jul 30];17(2):616-34. Disponível em: https:// www.redalyc. org/articulo.oa?id=451856605011.

45. Rocha TMA, Gurgel PRH. Práticas parentais e análise do comportamento: o estado do conhecimento de teses e dissertações de 2010 a 2015. Série-Estudos. 2018;23(47):241-62. http://dx.doi.org/10.20435/serieestudos.v23i47.1084.

46. Freitas LMA, Alvarenga P. Interação pai-criança e problemas externalizantes na infância. PSICO. 2016;47(4):279-87. http://dx.doi. org/10.15448/1980-8623.2016.4.23170. 